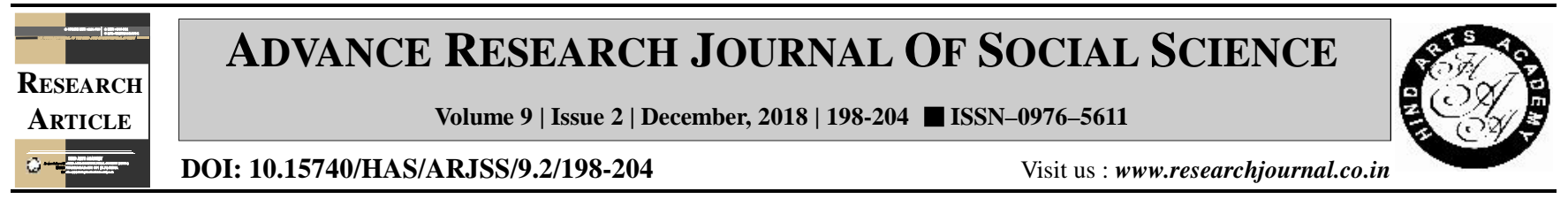

\title{
Factors affecting work ability among the workers engaged in different occupations
}

Pubali Saikia, Nandita Bhattacharyya and Moonty Baruah*

Department of Family Resource Management, College of Community Science, Assam Agricultural University, Jorhat (Assam) India

\section{ARTICLE INFO :}

$\begin{array}{lll}\text { Received } & : & 29.06 .2018 \\ \text { Revised } & : & 13.11 .2018 \\ \text { Accepted } & : & 16.11 .2018\end{array}$

\section{KEY WORDS :}

Work ability, Work

ability index, BMI

\section{HOW TO CITE THIS ARTICLE :}

Saikia, Pubali, Bhattacharyya, Nandita and Baruah, Moonty (2018). Factors affecting work ability among the workers engaged in different occupations. Adv. Res. J. Soc. Sci., 9 (2) : 198-204, DOI: 10. 15740/HAS/ARJSS/9.2/198-204. Copyright@2018:HindAgri-Horticultural Society

*Author for correspondence

\begin{abstract}
Work ability varies from occupation to occupations. Prevalent work related factors and reduced work ability of workers lead to different problems at work, results in low productivity, impaired health and safety of workers and sometimes early retirement. Therefore, improving work ability is one of the most effective ways to enhance the ability and preventing disability and early retirement. Keeping this in view a study was conducted among 60 workers engaged in two selected sectors of occupations (30 respondents from bank and 30 respondents from hospital) were selected purposively from Jorhat district of Assam with the objective- "To analyze the factors affecting work ability among the workers engaged in different occupations". Data were gathered by interview method. Work ability index was used to study the work ability of workers. Results shows that the workers were found to be subjected to adverse working conditions which lead to reduced work ability. The factors responsible for reducing work ability are shift work, long hours, with high pace of activity and work demand, mental load, physical load, etc. Work-related health hazards (body pains and injuries) and lost work time represent a significant changes in work ability the workers.
\end{abstract}

